\title{
«RETÓRICA»:
}

\section{APUNTES SOBRE LA PALABRA Y LA COSA}

\section{Francisco ABAD NEBOT}

\author{
Universidad Nacional de Educación a Distancia \\ fabad@flog.uned.es
}

\begin{abstract}
Resumen: Este artículo hace inventario de los que la lexicografía académica y no académica, los tratadistas del XIX y algunos autores del XX dicen sobre el significado de la palabra "retórica".
\end{abstract}

Résumé: Cet article présente une recopilation de ce que les dictionnaires, les traités du XIX siècle et quelques écrivains contemporains ont écrit sur le terme "Réthorique".

Palabras clave: Semiótica, Teoría Literaria, Retórica.

Mots clé: Sémiotique, Théorie Littéraire, Réthorique. 


\title{
1. EL TESTIMONIO DE ALFONSO $X$
}

Anotaremos simultáneamente algo acerca de la palabra (y la cosa) retórica. Esta voz retórica se tiene por documentada ya en el castellano de la Edad Media, y en particular desde Alfonso X.

Recogiendo para lo medieval -y sin notas eruditas a las que remitimos, y con alguna glosa nueva- varios textos que aparecen en nuestra Introducción a las doctrinas literarias en España (2004), podemos testimoniar cómo el rey Alfonso escribió efectivamente en el Setenario:

\begin{abstract}
Rrectórica llaman a la terçera partida destas tres, que sse entiende que enssenna a ffablar ffermoso e apuesto, e esto en siete rrazones: color, fermosura, apostura, conueniente, amorosa, en buen son, en buen contenente. Ca esto conuyene mucho al que desta arte husare, que cate que la rrazón que ouiere a dezir, que la colore en manera que paresca bien en las uoluntades de los que la oyeren. Et la tenga otrosí por ffermosa, para cobdiçiarla aprender e saberla rrazonar. Et que sse diga apuestamiente, non mucho apriessa nin mucho de uagar. Et que ponga cada rrazón allí do conuiene ssegunt aquello que quisiere ffablar. E que lo diga amorosamiente, non muy rrezio nin muy brauo nin otrosí muy fflaco; mas en buen sson mesurado, non altas bozes nin muy baxas. Et ha de catar que el contenente que touyere, que sse acuerde con la rrazón que dixiere. Et desta guisa sse mostrará por bien rrazonado aquel que rrazonare, e mouerá los coraçones de aquellos que lo oyeren para adozirlos más ayna a lo que quisiere. [...] La rrectórica, que es rrazón ffermosa e apuesta, se entiende por el Spíritu Ssanto; ca él alunbra e da color e ffermosura a todas las cosas que sson oscuras de entendimiento.
\end{abstract}

Subraya Alfonso que se advierta y tenga en cuenta, que se examine o juzgue lo que haya que decir (invención), que se ponga cada razón en el lugar adecuado (disposición), y que se ornamente o colore (elocución), de tal manera que eso que se dice resulte de esta manera persuasivo.

Se trata pues entre otras cosas de que los discursos tuviesen ornato o viveza para que parezcan bien y se tengan por hermosos, y de esta manera se aprendan.

En realidad Alfonso trata aquí de "tres ssaberes" que son la "gramática", la "lógica" y la "rrectórica", y afirma que los tres "sse tornan en vna rrazón" y así "touyeron por bien los ssabios que sse deuían contar por vna arte, e pusiéronla por entrada a las otras". 
Distintamente hace referencia Alfonso el Sabio a las que él dice "artes aque llaman liberales" en el capítulo XXXV de la Primera Parte de la General estoria; delimita ahora el "triuio" del "quadruuio" y respecto del primero declara que las artes del trivium "muestran all omne dezir razon conueniente, uerdadera e apuesta". Tales artes del trivium resultan tres, a saber: "gramatica", "dialetica" y "rectorica", y el rey especifica así la tercera:

La rectorica otrossi es art pora affermosar la razon e mostrar la en tal manera, quela faga tener por uerdadera e por cierta alos que la oyeren, de guisa que sea creyda. Et por ende ouo nombre rectorica, que quiere mostrar tanto como razonamiento fecho por palabras apuestas, $e$ fermosas e bien ordenadas.

La voz "arte" en esta expresión artes liberales o artes dignas del hombre libre, significa 'doctrina', y el monarca castellano recoge una versión de ellas y las enuncia en un orden determinado: proclama en concreto cómo el trivium comprende la lógica o razonamiento y la expresión.

\section{EN EL OTOÑO MEDIEVAL}

Contamos como de muy principios de la tercera década del XV, aunque acabada en la siguiente, con la traducción que hizo el obispo de Burgos D. Alonso de Cartagena del De inventione ciceroniano. En el "Prólogo y Dedicatoria" del libro, Cartagena se manifiesta con estas palabras:

Algunos cuidan que la rethórica toda consiste en dar dotrinas espeçiales para escrivir o fablar o trasmudar o ordenar las palabras, [...] pero non es éste su total intento, ca grande parte d'ella se ocupa en enseñar cómo deven persuader e atraer a los juezes en los pleitos e otras contiendas, e a las otras personas en otros fechos quando acaescen.

E quien bien lo quisiere considerar fallará que el ofiçio que entre nos tienen los juristas que llamamos abogados, ése era prinçipalmente el de los rethóricos antiguos.

La Retórica consiste así en una doctrina para la elocución y una doctrina para el logro de la persuasión. Nuestro obispo vemos que pondera en particular efectivamente el carácter persuasorio que ha de tener la retórica, que no es sólo por tanto una manera 
de hablar o de escribir con ornato, sino que posee una finalidad actuativa; se trata de lo que se ha llamado un concepto clásico de la Retórica, abierto a lo moral y sociopolítico. Así las cosas, de ello ocurre que los príncipes de la elocuencia "dieron sus generales doctrinas para argüir e responder, para culpar e defender e para mover los coraçones de los oyentes a saña o a misericordia o a las otras pasiones que en la voluntad humana cahen".

Vendrá luego Villena, autor de una Traducción y glosas de la “Eneida” o "traslado de latín en romançe castellano de la Eneyda de Virgilio, la qual romançó don Enrique de Villena", y en la misma don Enrique hace empleo del vocablo retórica y la tiene además en tanto una leche o alimento:

Leche llamó a la doctrina de la rectórica porque es dulce como la leche e más se deleyta en ella el entendimiento quel gusto en lo dulçe; e aun porque se deve aprender en la tierna hedat, porque es más fáçil que la poesía, a cuyo respecto ésta leche puede ser dicha.

Autores paganos y cristianos hicieron uso de metáforas de alimentos en la Antigüedad y en la Edad Media, según anotó ya Curtius, pues se refieren a la retórica o a la poesía por ej. -según vemos- en tanto alimento espiritual.

Hay de otra parte una glosa -la primera que acompaña al texto virgiliano traducido por nuestro autor, luego del preámbulo o prohemio-, en la que Villena establece "las razones porque los poethas escrivieron sus obras figurativamente", y enumera cuatro, a saber:

La primera, porque fuese común a todos, ansí que los moços lo oviesen por patraña e los de mayor hedat e non letrados, por ystoria; los letrados, por allegoría e, allende desto, secretos de natura e moralidades en ello especular podiesen. La segunda, por fablar breve; que pudiesen dezir en pocas palabras mucha sustançia. La teçera, porque los exponedores oviesen materia general en que diversas fiziesen exposiçiones. La quarta, por encubrir a los malos la materia de los viçios de que avíen de tractar, reprehendiéndolos porque non aprendiesen nuevas maneras de culpas.

Se trata así de que el discurso encierre moralidades, de que consista en un "fablar breve", de que haya materia para el comentario, y de que el tratamiento de los vicios resulte encubierto por razones de prudencia moral; el hecho aludido de la 
brevedad como ideal estilístico viene de la tradición de la Antigüedad, y en la Edad Media "muchos escritores citarán las fórmulas de brevedad a fin de probar que están familiarizados con los preceptos retóricos”, según ha analizado el mismo Curtius.

Los discursos poéticos tienen naturaleza alegórica, se nos proclama. Los poetas hablan en efecto de manera velada para que pueda darse lugar a las exposiciones y glosas de los demás, hemos visto que manifiesta Villena, y es lo que repite asimismo al final de la traducción de este Libro I de la Eneida: "E por eso fablaron los poethas en esta velada manera, porque pudiesen los exponedores varias e útiles declaraçiones fazer".

\section{EL SEISCIENTOS}

A principios del XVII -por hacer otra ilustración acerca de la palabra (y la “cosa") retórica- encontramos la bella Elocuencia española en arte de Bartolomé Jiménez Patón. El autor se refiere a su trabajo como un "arte y preceptos de Rhetórica o Eloquencia Española": la voz retórica vemos que la parafrasea sinonímicamente como "eloquencia"; además indica que tal trabajo "se endereça a servir a nuestros Españoles", lo cual supone la manifestación de un sentimiento protonacionalista, pues se trata de ayudar mediante la escritura de un libro a la comunidad tradicional de los connacionales.

Luego Bartolomé Jiménez da una versión del saber retórico y define y aclara así:

La Rhetórica es un arte que enseña adornar la oración, lo que se habla y dize; sus partes son dos, elocución y ación. [...] La invención y disposición son partes de la Dialéctica y no de la Rhetórica. [...] La ación es como eloquencia del cuerpo [,...] y así la hazemos parte de la Eloquencia.

Tenemos pues elocución y acción; la segunda de ellas forma también parte de la retórica o "elocuencia" (voces estas últimas que otra vez encontramos como sinónimas). En particular la elocución "es un adorno de lo que se dize. Sus partes son dos. Tropo y figura”. 
Como algunas veces se ha dicho, la de Jiménez Patón es la primera Retórica hecha en verdad a la vista de nuestra lengua vernácula; hace estimación ya -además- del Quinientos castellano.

\section{EN EL SETECIENTOS}

En el año 1757 aparece la "Rhetórica" de don Gregorio Mayans, el cual anticipa ya en los preliminares "a los letores" que es "el fin de la Rhetórica buscar los medios de persuadir; i el fin del rhetórico práctico, que llamamos orador, la persuasión”, y añade que por ejemplo la Gramática tiene por objeto "la pureza de las dicciones que han de componer la oración", etc.

Ya en el cuerpo de su amplio texto estampa don Gregorio estas consideraciones que copiamos:

Rhetórica, según Isócrates, es la ciencia de persuadir; esto es, el arte que enseña el modo de hacer una oración eloqüentemente persuasiva.

Arte es una junta de reglas que enseñan los más fáciles modos de hacer alguna cosa útil [...]. El oficio del rhetórico es hallar los medios convenientes para hacer una oración persuasiva.

Es pues su fin persuadir hablando; i el que egecuta esto con perfección, se llama orador; i por esta caisa la rhetórica rambién se dice oratoria.

La retórica consiste por tanto en el arte o conjunto de reglas para persuadir; se la conoce asimismo como oratoria, dado que es obra o resultado del oficio de orador. 


\section{LA PALABRA “RETÓRICA” EN LA LEXICOGRAFÍA ACADÉMICA}

El vocablo retórica en tanto sustantivo lo registra en 1737 el conocido como Diccionario de Autoridades (Tomo Quinto), que define que es 'el arte de bien hablar', e indica asimismo que "usado en plural vale la abundancia de palabras y sophisterías, de que alguno usa para engañar, ò excusarse de hacer alguna cosa". Hasta la "sexta edicion" del DRAE (1822) llegan aproximadamente estas mismas palabras, y luego en la trayectoria del léxico oficial encontramos hechos como estos:

1. En 1832 la forma en singular se define así: 'el arte de bien hablar y de ordenar rectamente un discurso'.

2. La "novena edicion" (1843) remite en la entrada retórica a la de oratoria, y en ella se dice: 'arte de hablar y escribir con propiedad y elegancia'.

3. La innovadora edición del DRAE de 1884 define de esta manera: 'arte de bien decir, de embellecer la expresión de los conceptos, de dar al lenguaje escrito ó hablado eficacia bastante para deleitar, persuadir ó conmover'.

4. En el mismo año 1884 el Diccionario indica a la letra que usada la palabra en plural y en el habla familiar significa 'sofisterías ó razones que no son del caso', dato que en realidad venía ya -según hemos visto- de Autoridades.

5. Tomada la palabra en singular, el DRAE de 1956 suma a la acepción de 'arte de bien decir, ...' una segunda que dice también a la letra: “despect. Uso impropio o intempestivo de esta arte".

6. La "vigésima segunda edición" de 2001 añade otra acepción, la que hace de la retórica la 'teoría de la composición literaria y de la expresión hablada', y conserva todas las indicaciones anteriores. Sin duda esta acepción últimamente incorporada responde a las referencias que en los manuales de enseñanza media de nuestros días se han hecho a veces al arte de componer textos, según vamos a ver en uno del prof. Fernando Lázaro. 


\section{CONCEPCIONES DE LOS TRATADISTAS DEL OCHOCIENTOS}

Francisco Sánchez [Barbero] trató en los Principios de Retórica y Poética (1805) que escribió (1834: 103) de "las diferentes especies de Locucion pública", y decía allí que "todos los discursos se pueden reducir á alabar la virtud, y reprender el vicio (de este género son los sermones, los panegíricos, las oraciones fúnebres, las gratulatorias y las invectivas): á persuadir o disuadir una accion en las asambleas generales, en donde se delibera acerca de los intereses de una nacion: á la defensa ó acusacion de un particular, ó de sus derechos en presencia de los jueces, que han de fallar segun la equidad y las leyes". Lo oratorio queda concebido pues con una finalidad de alabanza o vituperio, de persuasión, de defensa, ...

La Filosofia de la Eloquencia de Antonio de Capmany en su segunda edición (1812) distinta de la primera, proclama cómo "el fin de la eloqüencia es adornar la oracion con las galas y luces del estilo", por lo que él dice que se ocupa en su texto de la elocución; asimismo se ocupa de "la pronunciacion con la accion" o eloquentia corporis, y define en fin: "Llamo yo filosofia de la eloqüencia aquella sabiduria, aquella discrecion en producir con vigor, gracia y propiedad de palabras lo que se engendra en nuestro discurso". La propiedad y la expresividad elocutivas da lugar así a la elocuencia.

Pasadas las enunciaciones generales, Capmany hace ya una exposición más concreta y señala entonces que los retóricos dividen la elocución en dos partes principales, a saber: "eleccion de las palabras, que es la diccion; y composicion ó conveniente colocacion de ellas, que es el estilo"; este estilo oratorio "pide elegancia, grandeza, y dignidad", escribe: el orador debe "sentir, pensar, y pintar", de tal manera que "no puede alcanzar su fin sin los afectos". La elocuencia pide por tanto grandeza y sentimientos, subraya don Antonio (1812: III-VII, 59, 164).

Otro Antonio, Gil de Zárate, aboga (1844: 11) por la belleza externa de los escritos, de tal modo que ha de tenerse presente cómo dos cosas son las que constituyen cualquier escrito en prosa o verso: los pensamientos, más las palabras con las que vienen expresados. Resulta así que "el pensamiento constituye la bondad intrínseca de un escrito; el lenguaje su belleza esterior". 
A su vez don Alfredo Adolfo Camus se hace eco en el Curso elemental de Retórica y Poética (1854: 80-82) de la definición que dice que la elocuencia es "el arte de hablar de manera que se consiga el fin para que se habla", es decir, que la elocuencia puede emplearse para persuadir, para instruir o para agradar; mirando a lo esencial y simplificadamente, puede decirse también que la elocuencia es "el arte de la persuasión".

Hay -recoge Camus- tres grados de elocuencia, el que únicamente mira a agradar (un panegírico, etc.); el que se aspira "á informar, á instruir, á persuadir"; y "aquel en que el orador trata de inspirarnos sus pasiones, nos hace entrar en sus sentimientos, y nos dispone á resolver ó á obrar con fuerza y con calor". La persuasión inducida oratoriamente resulta por tanto un continuo que va desde hacia ninguna -caso de los que buscan sólo agradar y dar lugar a una pieza de arte-, hasta el máximo en que la palabra se resolverá en la acción que por su parte emprendan los interlocutores o destinatarios del discurso.

El Tratado de Retórica y Poética de Pedro Felipe Monlau (1866:1-3) se inicia con la noción de que "la Retórica es el arte de hablar y escribir de la manera mas acomodada al fin que nos proponemos", esto es,

La RETÓRICA [...] es un ARTE; es el arte de hablar y escribir; es una coleccion de REGLAS, una série de principios verdaderos, inmutables, y fundados en la naturaleza misma del hombre, los cuales nos enseñan lo que debemos hacer, y lo que nos es preciso evitar, para hablar ó escribir de la manera más acomodada al fin que nos proponemos.

Cuando el hombre habla o escribe -razona Monlau- se propone comunicar sus pensamientos y afectar el ánimo de quien le oye o lee: ocurre así que la Retórica se ocupa de las reglas para expresarnos de manera inteligible (lo que constituye la "Gramática"), y de las reglas que nos permiten expresarnos de acuerdo con el fin particular que nos proponemos (lo que es la "Retórica" propiamente dicha); para hablar gramaticalmente -concluye nuestro autor- basta hablar correctamente; para hablar retóricamente se necesita además "hablar adecuadamente al fin que se propone" quien habla, escribe, diserta, etc.

En lo que ahora nos importa, Joaquín Espar (1912: 17) definía que "Retórica es el arte de hablar para persuadir, y tiene por principal objeto el discurso oratorio; pero 
hoy se le da un sentido algo más lato, y se define el arte de bien decir": trata así no ya del discurso oratorio, sino por igual "de todas las composiciones literarias en prosa".

Espar escribe en la mitad del Ochocientos, y se reedita ya en el siglo XX en versiones reformadas por otros autores (nosotros tenemos delante -según queda indicado- una de 1912), y a esa segunda mitad del XIX ha de referirse en general el sentido amplio de 'arte de bien decir' que atribuye a lo retórico. Además y también en coherencia con esto delimita la "Retórica" en cuanto suma de reglas para cualquier composición, de la "Oratoria", en cuanto en ella el orador no sólo sabe las reglas retóricas sino que "las ejercita perorando".

Autor que ha pasado a ser representativo de nuestros tratadistas de Retórica del Ochocientos es don José Coll y Vehi, quien argumentaba (1870: 176-177) que

en los momentos supremos de la vida, siempre que una circunstancia extraordinaria conmueve profundamente nuestro ánimo, apenas hay hombre que no sea elocuente. Pero el arte, apoyado en la naturaleza, ha conseguido que la palabra humana, subordinada á la reflexion y dócil instrumento de la voluntad, se convirtiese en arma poderosa de la verdad, de la justicia, de la moral y de la religion. De aquí ha nacido la oratoria [...] ó arte de emplear el pensamiento y la palabra para la consecucion de un fin determinado, que generalmente es la aplicacion de la verdad (general ó abstracta) á un caso particular, la realización de lo útil y de lo bueno.

El hablar humano resulta de esta manera un instrumento de la voluntad aplicado a la consecución de un fin, y en esto reside la elocuencia u oratoria: Coll definirá así que "la retórica es la teoría de la oratoria ó de la elocuencia".

De acuerdo con ideas que ya hemos visto apuntadas, el profesor don Diego Manuel de los Ríos, en unas Instituciones de Retórica y Poética que dio a luz, sintetizaba (1878: 1) que la Retórica “es el arte de bien decir", y que se distingue de la Gramática en que esta segunda se limita a la corrección del idioma, mientras la Retórica enseña a hablar del mejor modo "conducente á un fin determinado".

De la Retórica y Poética ó Literatura Preceptiva por Narciso Campillo y Correa vamos a recoger solamente -a manera de ilustración- el párrafo que dice (1909: 168):

Llámase discurso oratorio todo razonamiento dirigido á convencer y persuadir. Es razonamiento porque consta de una serie de razones mutuamente enlazadas; procura convencer, porque habla á la inteligencia con pruebas, y tiende á persuadir, estimulando la voluntad con la moción de los afectos. 
Analiza aquí Campillo los diferentes momentos del convencer y el persuadir, ambos integrantes del discurso oratorio en efecto.

Algo más complicado quizá se muestra en las nociones y definiciones Ángel María Terradillos (1872), pese a que lo hace en unas Lecciones elementales de Retórica y Poética; recoge a su vez la idea de que la Retórica es el conjunto de preceptos que llevan a emplear la palabra -hablada o escrita- de la manera más conveniente al fin propuesto, Antonio González Garbín en un Compendio de Retórica y Poética ó de Preceptiva Literaria (1891: 17). Definía en cambio la Retórica como el arte que enseña a expresar el pensamiento por medio de la palabra simplemente "con la mayor belleza posible", el tratadista don José V. Rubio Cardona en su Compendio de Retórica y Poética (1896: 44).

\section{DATOS DE LA LEXICOGRAFÍA NO ACADÉMICA}

Antes de que existiese la Academia, Covarrubias definía escuetamente en la entrada retórica: "Es un modo de hablar con harte y compostura".

Terreros en su Diccionario castellano da una acepción según la cual retórica significa 'eloqüencia, arte de bien hablar, arte de persuadir', y trae también otras: 'la clase en que se enseña'; 'el libro que la enseña'. Luego Salvá equipara en primer lugar en tanto sinónimos retórica y oratoria, y en este segundo vocablo define: 'arte de hablar y escribir con propiedad y elegancia'; además añade estas acepciones, a saber: 'el arte de bien hablar de la elocuencia'; 'las reglas y preceptos de este arte'. Se trata pues en uno de los sentidos del arte de bien hablar de la elocuencia, es decir, del arte que consiste en 'persuadir al lector ó al oyente, y de conmover su ánimo por medio de la palabra'.

Vemos en todo caso dos acepciones principales, una que se refiere a lo propio o característico de la elocuencia, y otra -metateórica (diríamos)- referida al total o conjunto de las reglas de esa elocuencia.

Ramón Joaquín Domínguez manifestó en la entrada retórica que se trataba de "el magnífico arte de la oratoria, fecundo en imágines, figuras ó metáforas sublimes": parece hacer sinónimas por tanto las voces oratoria y retórica, y en esta segunda entendida como sustantivo- nos da un texto que debe recogerse porque introduce matizaciones: 
Arte que enseña á ser orador. En esta acepcion, la oratoria es una parte de la retórica; pero muy comunmente se suele toma por la retórica misma, en cuyo caso la oratoria enseña á escribir y hablar con propiedad y con elegancia, sacrificando muchas veces la primera de estas cualidades á trueque de conseguir la segunda.

La oratoria se nos dice que está entendida generalmente como la retórica toda, y que busca el buen logro elocutivo y del gesto (y la persuasión, cabría añadir), e incluso más veces la elegancia que la propiedad idiomática.

El relevante Diccionario Hispano-Americano de literatura, ciencias y artes ("tomo décimoséptimo", 1895) copia sus definiciones del léxico oficial académico de 1884, si bien las ilustra con textos, e incluye además unas consideraciones enciclopédicas y no ya solamente léxicas. Dice así por ej. este Diccionario: "Algunos, siguiendo á Aristóteles, la han definido como la facultad de determinar todos los medios posibles de persuadir [...]; otros, con Quintiliano, la han definido como el arte de bien hablar, añadiendo con él, que esta definición comprende, condensada en una palabra, todas las palabras y costumbres del orador, puesto que para ser buen orador es indispensable ser hombre de bien". Pero más sustantivamente y más allá de este esbozo de indicación histórica nuestra obra proclama que la Retórica "no es el arte mismo, sino la teoría del arte, es decir, el conjunto de reglas que conviene seguir para llegar al fin. Es [...] la teoría de la elocuencia"; se denomina en propiedad retórica -vemos- a lo que es teoría o metateoría, según decíamos antes.

Más adelante escribe el Diccionario Hispano-Americano: "Sus preceptos relativos á la elocuencia no se aplican solamente al discurso, sino á toda obra literaria; es la teoría del arte mismo de la composición. Ella nos enseña [...] á considerar en la preparación del discurso tres partes: la invención, la disposición y la elocución.[...] Los hechos ó las ideas, el orden ó el plan, la ejecución ó el estilo, todo se halla comprendido en estas tres partes [...;] ]existe no obstante otra cuarta parte, la acción, construída por la cohesión íntima de las otras tres".

En fin y de manera específica, nuestro texto concretará que "la elocución considera el estilo"; etc.

El Gran Diccionario de la lengua castellana por Aniceto de Pagés continuado [...] por José Pérez Hervás se hace eco asimismo del Diccionario académico (en este caso el de 1884), añade textos que ilustran o autorizan las acepciones, y añade asimismo 
estas dos acepciones del vocablo: "Retórica: Clase donde se enseña esta asignatura. [...] Tratado de la misma"; queda subrayado por tanto el carácter doctrinal o de teoría que algunos autores -tal como queda visto- han advertido.

De nuevo el eco del léxico oficial se halla presente en otra obra muy representativa: nos referimos a la Enciclopedia Vniversal Ilvstrada Evropeo-Americana, la obra que coloquialmente se conoce como el Espasa. Estamos ante un repertorio no sólo léxico sino enciclopédico, y en este sentido nuestra voz aparece con ilustraciones doctrinales una de las cuales dice que según algunos"la Retórica no es el arte mismo, sino más bien la teoría del arte, es decir, una colección de reglas que nos enseñan lo que debemos hacer y lo que es preciso evitar para conseguir el fin que nos proponemos"; se apunta aquí más o menos la variación o escisión semántica notada ya por Vicente Salvá y que da lugar a dos acepciones (o subacepciones) separables.

La Enciclopedia Vniversal... cita a Francisco Navarro Ledesma para recoger su idea de que hay muchas obras literarias "de las cuales no podrían tratar en rigor la Poética sola, ni la Retórica sola, sino que de ellas trata la Retórica y Poética ó Preceptiva literaria".

De otra parte enseña esta Enciclopedia que los tratadistas consideraban en la obra literaria los elementos de invención, disposición y elocución: "Como tales elementos -argumenta- no podían ser exclusivos de un discurso, una epístola, una narración histórica ni una obra didáctica, sino que las obras poéticas (epopeya, oda, drama, fábula, etc.) también debían contenerlos, de ahí arrancaba que la Retórica se confundiese con la Poética", lo que -ha dicho en nuestros días y por su cuenta Roland Barthes- sucede aproximadamente en la época de Ovidio y Horacio y un poco después (Tácito).

Llegados al siglo XX, el diccionario VOX que revisó Gili no hacía en la voz retórica sino simplificar y tomar a la letra la definición académica, por lo que decía así: 'arte de bien decir, de dar al lenguaje eficacia bastante para deleitar, persuadir o conmover'.

A su vez doña María Moliner remite en retórica a oratoria en cuanto se trata del 'arte de pronunciar discursos', y define asimismo en otra acepción: 'Conjunto de principios y reglas referentes al arte de hablar o escribir literariamente'. 
Por su parte el Diccionario del español actual y el Diccionario abreviado del español actual de Seco, Andrés y Ramos dice en resumen: "Técnica de hablar o escribir de manera persuasiva y eficaz. b) Habilidad [de una pers.] para expresarse con persuasión. c) (desp) Forma de expresión excesivamente artificiosa y falta de contenido".

En fin La Enciclopedia de Salvat-EL PAIS (tomo 17, 2003 [realmente 2004]) recoge entre otras cosas este pasaje más adecuado que otros de muchos autores:

La elaboración del discurso retórico comprende cinco fases: a) la inventio, en la cual se hace una selección de argumentos e ideas que hacen probable el tema y que se dividía en cuatro partes (el exordio, la narración, la argumentación y la peroración); b) la dispositio, en la cual se ordena y se dispone todo lo propuesto por la inventio; c) la elocutio, que es la realización material de lo planificado en la inventio y en la dispositio, haciendo uso de tropos, figuras de dicción y de sentencia; d) la memoria, o retención de las tres fases previas; y e) la pronuntiatio, que incluye tanto los sonidos y la entonación como los gestos (actio) del orador.

Por supuesto hay (hoy) muchos diccionarios y cabría hacer un examen más extenso, aunque no sabemos si en verdad daría rendimiento lexicográfico o doctrinal.

\section{MENÉNDEZ PELAYO}

Don Marcelino tiene algunas alusiones a la retórica en la Historia de las ideas estéticas en España, a la vez que con toda naturalidad -como es lógico- hace uso de la voz; por ej. al ir desarrollando la exposición de Quintiliano estampa estas palabras: "El orador tiende a la victoria por medio de la persuasión; pero aunque no la logre, consigue el fin del arte cuando habla conforme a él, porque la oratoria tiene su fin en sí misma, el cual no es otro que el bien decir. [...] Consta la retórica de prescripciones enlazadasentre sí y enderezadas juntamente a un fin útil para la vida humana [...]. La retórica pertenece al género de las artes que terminan en su propio acto". Cabría decir por nuestra cuenta que la Retórica es a la vez una finalidad sin fin y una finalidad utilitaria: en lo que tiene de artística es finalidad desprovista de fin, y en lo que tiene de perseguir un fin útil posee finalidad utilitaria, interesada. 


\section{HEINRICH LAUSBERG}

A la definición de la materia dedica Lausberg los $\S \S 32$ y ss. de su necesario Manual de retórica literaria, en el que se hacen algunas caracterizaciones como estas:

a) La definición de "Retórica" es la de ars bene dicendi; también existe la de bene dicendi scientia -el aprendizaje de la ars conduce a la scientia-. En cuanto bene dicendi scientia la retórica se contrapone a la teoría gramátical, que se define como scientia recte loquendi: de esta manera la "virtus" de la gramática consiste en la corrección, y la de la retórica en el bene. "Las virtutes de una ars designan [...] tanto una perfección de la obra (opus), indicada aquí por el dicendi, como también una perfección del artifex (en este caso, del orator)".

b) "La retórica, gracias a sus partes memoria y actio, se caracteriza como arte práctica (esto es, como arte de representación, igual que el arte dramático, por ejemplo), mientras que las partes inventio, dispositio y elocutio [...] son una preparación poiética de la ejecución práctica (llevada a cabo mediante la memoria y la actio)".

c) Tanto la retórica -en sus partes inventio, dispositio y elocutio- como la poética, son ciertamente artes poiéticas en el dominio del idioma; no obstante al paso que el orador ve su officium en influir sobre el público, el

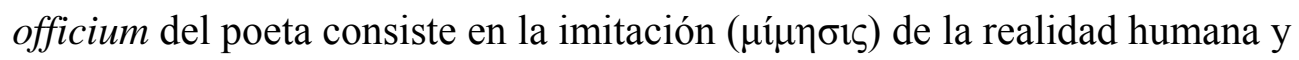
no humana. "Ahora bien, la crítica literaria [...] es el aspecto "teórico" tanto de la poética como de la retórica [...]. Y así, la relación de la poética con la retórica es, por tanto,muy íntima: el terreno común para el poeta que compone y para el orador que ejerce es la mutua compenetración de ambas artes en los artistas creadores [...]; el terreno común de ambas artes para el público que goza de la literatura es la crítica literaria”.

Cabe recordar asimismo que Roland Barthes, al disponerse a tratar de "La antigua retórica" al frente de un conocido número monográfico de revista, parafraseaba el concepto de "retórica" en tanto una técnica, una enseñanza, una ciencia, etc. En fin 
podemos mencionar a Francisco López Estrada, quien sintetiza así en su manual de Introducción a la literatura medieval española:

La Poética (en términos generales, señalando las bases de la constitución del hecho literario) y la Retórica (reuniendo en forma ordenada los formulismos expresivos caracterizadores de este hecho) constituyeron desde la época griega sistemas organizados de los recursos con que la lengua se perfeccionaba mediante el ejercicio de un arte que podía enseñarse y aprenderse para luego ser reconocido en la obra literaria.

Las formas literarias y elocutivas dan lugar en efecto a cada texto: se trata ciertamente de un arte que cabe enseñar y aprender, y que luego cabe analizarlo en la serie artística.

\section{RETÓRICA Y ENSEÑANZA}

En los años cuarenta del siglo pasado los libros de texto de una asignatura del cuarto curso del Bachillerato llevaban la denominación de "Preceptiva literaria y Nociones de gramática histórica" y también "Teoría de la literatura y Gramática histórica del español”, etc. Autores solventes -Díaz-Plaja, Blecua, Ferreres, Lapesa, ...hicieron tales obras (en un solo volumen o en dos, uno por materia), y nos cabe ver cómo presentaban la Retórica.

Guillermo Díaz-Plaja (1943: 175-176) dice así: “El poder de persuasión que hoy día tiene el periodismo estaba antiguamente ceñido al arte oratorio. Los viejos libros de preceptiva llaman a la oratoria «el arte de persuadir»; enseguida, y aunque en una acepción pueden identificarse retórica y oratoria, enseña: "La teoría de la oratoria se llama retórica". Delimita luego las partes del discurso (exordio, proposición, confirmación, refutación y peroración), y distingue asimismo las diferentes clases de discursos (oratoria sagrada, forense, política, académica, militar).

José Manuel Blecua (1944: 72-75) define de esta manera:

Es la oratoria el arte de convencer, persuadir o conmover a un público por medio de la palabra. El orador emplea, además de la palabra, los gestos y los ademanes. La elocuencia es cierto don de la naturaleza, que se perfecciona por medio del arte, de un aprendizaje severo. Pero lo que caracteriza la oratoria frente a la poesía es la subordinación a un fin útil y 
práctico, como la reforma de una ley, la propaganda de una idea, la defensa de un reo, etc., y también el contacto que se establece con el público.

Nuestro autor subraya lo que tiene de utilitario el discurso retórico u oratorio, frente a la finalidad que se considera desinteresada o propiamente estética de la poesía (=de la literatura). Ya antes efectivamente, en este mismo manual (1944: 53), había presentado una división de los productos literarios en dos grandes grupos, a saber: “obras poéticas, cuya esencial finalidad es la creación de belleza (estén escritas en prosa o verso), y obras cuyo fin no es la creación de belleza sino la demostración de una verdad, como la oratoria o la didáctica, aunque no por eso la belleza esté ausente de estas producciones".

Luego enumera Blecua las partes del discurso, y añade que si la proposición "comprende varios puntos, éstos se enumeran sucesivamente, a lo cual se llama división"; también enumera los géneros del discurso (oratoria sagrada, forense, ...).

Un distinguido estudioso como don Rafael Ferreres publicó a su vez en 1946 el aludido texto Teoría de la literatura y Gramática histórica del español, y en el mismo enseñaba (1946: 110-111): "La oratoria es tanto como el arte de hablar públicamente con un fin persuasivo. [...] Se ha de expresar [...] el orador de manera bella, pero sin olvidar el fin práctico que procura alcanzar". Distingue luego Ferreres al igual que sus colegas las partes del discurso oratorio y las clases de oratoria o géneros de la misma eran asuntos que debían venir exigidos por los programas oficiales-, y respecto de lo primero especifica específica con mayor detalle y mantiene: "En la proposición dice [el orador] de qué va a tratar. Si toca varios puntos los separa por medio de la división. [...] En la narración expone persuasivamente la cuestión. [...] En la confirmación [...]”.

El entonces joven Rafael Lapesa fue autor de dos textos que respondían a la asignatura de cuarto curso de Bachillerato que queda aludida: nos referimos a los volúmenes Formación e historia de la lengua española (1943) e Introducción a los estudios literarios (1947); la primera de las presentes obras parece haber pasado completamente inadvertida; la segunda cuenta con reediciones desde los años sesenta que la hacen llegar al mercado aún en nuestros días, y no debe ser avalorada sin tener en cuenta que se trata de un manual de Bachillerato.

La manera de presentar la materia por parte de Lapesa es así (1947: 178 y ss.): 
Oratoria es el arte de convencer o conmover por medio de la palabra hablada. La obra oratoria puede proponerse la mera exposición de conocimientos o hechos, como sucede en la oratoria académica. Pero generalmente trata de persuadir al auditorio para que adopte una resolución o se decida a obrar de determinada manera. El fin práctico de la oratoria deja en segundo término al literario: lo importante en el discurso es que sea eficaz; la belleza es añadidura, tanto más conveniente cuanto más contribuye a mover el ánimo de los que escuchan.

Podría decirse pues, según esto, que la finalidad práctica de la oratoria se manifiesta según grados en cada discurso, pero que tiende a ser máxima, y que su finalidad estética se manifiesta asimismo según grados que van desde uno muy pequeño hasta otro apreciable o incluso notorio.

Nuestro autor no dejó de referirse asimismo a las cualidades del orador, y sobre ello manifestaba:

La elocuencia necesita apoyarse en activo sentido lógico que permita hallar rápidamente los argumentos necesarios, armazón del discurso; complemento de la lógica es una imaginación viva que tenga siempre dispuesta la expresión vigorosa, justa e impresionante; y es imprescindible una intuición profunda del alma de individuos y colectividades para encontrar en cada caso el tono conveniente, así como la argumentación y recursos que pueden causar mayor efecto.

Luego entra Lapesa en distinguir las partes del discurso, y a este propósito incluye unas claridades que quizá no se hallan expuestas con tanta nitidez en otros colegas suyos: "En la proposición -expone en efecto- el orador anuncia el tema de que va a tratar, y en la división las partes o cuestiones principales que el tema contiene. En la confirmación se demuestra la teoría sustentada alegando las pruebas necesarias, y en la refutación se invalidan los argumentos que se pudieran oponer. El epílogo es un resumen o conclusión; la peroración remata patéticamente el discurso para acentuar la emoción de los oyentes". Aparecen distinguidas con claridad así la "proposición” y la “división”, y además se delimita la "peroración” propiamente dicha del "epílogo". Hay que decir que a don Rafael nunca le fueron ajenos los saberes literarios, y que de hecho si no llegó a opositar a la cátedra de "Gramática General y Crítica Literaria" que había firmado fue porque se dotó la de "Historia del español” y concursó a ella; el trabajo de 
firma a la primera de estas titulaciones tenemos entendido que fue el que dedicó a la trayectoria poética garcilasista que inmediatamente publicó en la Editorial de la Revista de Occidente.

Más rápida y de menor detalle es la referencia que al género oratorio hicieron más tarde Evaristo Correa y Fernando Lázaro, en su texto de los años sesenta editado por Anaya, Lengua española y literatura. Cuarto Curso.

\section{RETÓRICA COMO TEORÍA ELEMENTAL DE LA COMPOSICIÓN LITERARIA}

Hemos visto arriba una acepción en la que en sentido más amplio que otros, retórica quiere decir 'teoría de la composición literaria y de la expresión hablada'; según decíamos, tal acepción responde seguramente a las referencias que en varios manuales de enseñanza media se han hecho a veces al arte de componer textos escritos.

Uno de esos textos es el manual para el antiguo COU que escribió el ya mencionado prof. Fernando Lázaro Lengua española: historia, teoría y práctica (19711972). Años antes este autor se había referido a la palabra y la cosa retórica lógicamente- en el Diccionario de términos filológicos que compuso, en el que en abreviatura decía así: "Retórica. En la Antigüedad, una de las artes liberales que se ocupaba de la construcción artística del discurso. En cuanto arte, constaba de cinco partes: inventio, dispositio, elocutio, memoria [...] y actio [...]. La materia de la retórica [...] comprende tres tipos de elocuencia: el discurso forense [...], el deliberativo [...] y el panegírico".

El aludido manual para el Curso de Orientación Universitaria tenía una parte llamada "Arte de escribir", y consistía en efecto en una abreviada 'teoría de la composición literaria'. Enseñaba así esta obra a la que nos referimos:

Al escribir hay que decir algo y presentarlo en un orden adecuado (son las partes de la Retórica denominadas invención y disposición respectivamente). [...] La invención es el arte de "hacer venir" las ideas [...] Salvo en el caso extremo en que se desconozca el tema por completo, todos somos capaces de extraer de nuestro recuerdo y de nuestra experiencia, ideas útiles para la elaboración de un escrito. Y mediante un cierto entrenamiento lógico, podemos valorar esas ideas y desechar las inútiles. 
En cuanto a la disposición u ordenación de las partes de un escrito, será también resultado de nuestra capacidad lógica. Esta impondrá a las ideas un orden, según cuál sea nuestra intención al escribir (exponer, narrar, describir, argumentar [...]), nuestro punto de vista, los efectos que deseamos producir en el lector, etc.

No son pues enseñables mediante reglas fijas ni la invención ni la disposición de un escrito. Pero sí podemos facilitar ambas operaciones mediante el estudio atento de escritos de calidad, que nos ilustre de cómo han procedido sus autores (1971-72: I, 25-26).

Vemos por tanto cómo se emplea didácticamente una retórica elemental en el arte de escribir, y cómo así la retórica se hace una 'teoría de la composición literaria' propedéutica o de iniciación.

En otro momento de su Lengua española: historia, ..., el prof. Lázaro recapitula y añade más explicaciones, que recogemos por fin:

La Retórica antigua distinguía, muy razonablemente, tres procesos que concurren en el acto de escribir: la invención (hacer venir las ideas), la disposición (ordenarlas) y la elocución (exponerlas). [... Estos tres procesos...] son normalmente simultáneos. [...].

En el momento de la invención será preciso descartar todas las ideas que no se refieran directamente al tema. [...] En efecto tan importante como acopiar ideas, es rechazar las inútiles o im-pertinentes. La disposición exige igualmente que entre las partes del escrito haya una trabazón y una proporción interna, de modo que se articulen y di[sp]ongan según su jerarquía (importancia), de mayor o menor o de menor a mayor, o según su orden lógico [...]. Por fin la elocución debe adecuarse exactamente a la naturaleza del tema (es decir, a la invención), y hasta a las partes del escrito que lo desarrollan (o sea, a la disposición) (197172: I, 122-123).

Nuestro autor insistirá también en el tomito segundo de su manual en que la retórica antigua estudiaba bajo el epígrafe elocutio todo lo referido a lo que en un escrito es propiamente idiomático.

Queda mostrado de esta manera el acceso hasta la enseñanza media de una idea escolar de la retórica, y de sus aplicaciones en tanto teoría elemental de la composición literaria al arte de escribir. 


\section{RETÓRICA E HISTORIA DE LA LENGUA}

Los datos anteriores constituyen material -entre otros muchísimos- para la historia de las doctrinas literarias en España y para la historia del castellano; vamos a decir dos palabras acerca de esta historia de la lengua. A manera de ilustración mínima en efecto- acerca de cómo los análisis retóricos proporcionan datos para elaborar una Historia de la lengua con menos esquematismos o juicios solamente intuitivos e impresionistas, puede recordarse por ej. el bien sabido artículo de Rafael Lapesa sobre "Los Soliloquios de Fray Pedro Fernández Pecha" (el texto de tales "Soliloquios" lo editó el P. Vega y puede encontrarse fácilmente en la Biblioteca Nacional).

Lapesa subrayaba en Fray Pedro "procedimientos del saber retórico" bebidos en la tradición patrística: amplificación, paralelismo de frases más similicadencia, antítesis, oxímoros, figura etimológica, etc., y su conclusión en cuanto a la trayectoria de la lengua decía que estos Soliloquios demuestran que hacia 1400 "era ya posible escribir en castellano obras donde el primor estilístico más amanerado se mantuviese continuadamente y sin desmayos, con dominio técnico que sobrepasa las intentonas pasajeras de don Juan Manuel”.

Contribución fundamentalmente dirigida a lo retórico pero que no cabe dejar inadvertida en cuanto ilumina los logros del idioma artístico, es la de varios artículos y el volumen de Luisa López Grigera (1994) La Retórica en la España del Siglo de Oro, en el que se llama la atención en particular sobre la tradición griega postaristotélicatanto helenística como bizantina.

En fin y por aludir a un tercer ejemplo, cuando C. Cuevas ha abordado los “Aspectos retóricos en la poesía de San Juan de la Cruz” (1992), ha hecho análisis de la presencia en el Cántico de la interrogatio, las diversas formas de apóstrofe, la similitudo, la repetitio, etc. Por supuesto podrían allegarse bastantes casos más de análisis retóricos que pueden contribuir en la tarea de hacer la Historia de nuestra lengua de manera menos esquemática -según decimos- que hasta ahora.

\section{DOS CONCLUSIONES}

De los párrafos anteriores cabe deducir -entre otras más- dos nociones: 
1. El DRAE hace equivalentes en un momento retórica y oratoria, aunque las diferencian -según criterios y razonamientos distintos-, Salvá, Joaquín Espar, Coll y Vehi, etc. Capmany deine además lo que entiende por "elocuencia".

2. El mismo DRAE introduce la idea (en 1884) de que lo retórico es un decir eficaz, persuasivo, emocional... Antes y después de esa fecha, los tratadistas de Retórica del siglo XIX tienden a subrayar mayoritariamente esa idea del decir eficaz, aunque no faltan quienes ven en lo retórico simplemente un decir artístico y bello. 


\section{REFERENCIAS BIBLIOGRÁFICAS}

ABAD, F. (2004). Introducción a la historia de las doctrinas literarias en España. Madrid: Editorial de la UNED.

Blecua, J. M. (1944). Preceptiva literaria y Nociones de gramática histórica. Zaragoza: Librería General.

CAmpillo, N. $\left(1909^{8}\right)$. Retórica y Poética ó Literatura Preceptiva. México: Herrero Hermanos, Sucesores.

CAmus, A. A. $\left(1854^{2}\right)$. Curso elemental de Retórica y Poética. Madrid: Villaverde.

CAPMANY, A. de (1812). Filosofia de la Eloquencia. Londres.

Coll y Vehí, J. $\left(1870^{4}\right)$. Compendio de Retórica y Poética. Barcelona: Diario de Barcelona.

Cuevas, C. (1992). «Aspectos retóricos en la poesía de San Juan de la Cruz». Edad de Oro XI, 29-41.

DíAz-PlajA, G. $\left(1943^{4}\right)$. Teoría e historia de los géneros literarios. Barcelona: La Espiga.

EsPAR, J. (1912 ${ }^{4}$. Arte de Retórica y Poética. Barcelona: Herederos de Juan Gili.

FERreres, R. (1946). Teoría de la literatura y Gramática histórica del español. Valencia: López Mezquida.

Gil de ZÁrate, A. (1844). Principios generales de Poética y Retórica. Madrid: Ignacio Boix.

GonzÁlez Garbín, A. (1891). Compendio de Retórica y Poética ó de Preceptiva Literaria. Granada: Vda. de Paulino Sabatel.

LÁZARO, F. (1971-1972). Lengua española: historia, teoría y práctica. Salamanca: Anaya.

LÓPeZ GrigerA, L. (1994). La Retórica en la España del Siglo de Oro. Salamanca: Universidad.

Monlau, P. F. $\left(1866^{6}\right)$. Tratado de Retórica y Poética. Madrid: Librería Clásica de la Publicidad.

Ríos, D. M. de los $\left(1878^{8}\right)$. Instituciones de Retórica y Poética. Madrid: G. Hernando.

Rubio Cardona, J. V. $\left(1896^{3}\right)$. Compendio de Retórica y Poética. Madrid: A. Marzo. 
SÁnchez [BArbero], F. (1834²). Principios de Retórica y Poética. Madrid: Imprenta de don Norberto Llorenci.

Terradillos, Á. M. (18727). Lecciones elementales de Retórica y Poética. Madrid: G. Hernando. 